\title{
The Effect of Perioperative Radiation Therapy on Spinal Bone Fusion Following Spine Tumor Surgery
}

\author{
Tae-Kyum Kim, M.D., Wonik Cho, M.D., Sang Min Youn, M.D., Ung-Kyu Chang, M.D., Ph.D. \\ Department of Neurosurgery, Korea Cancer Center Hospital, Korea Institute of Radiological and Medical Sciences, Seoul, Korea
}

\begin{abstract}
Introduction : Perioperative irradiation is often combined with spine tumor surgery. Radiation is known to be detrimental to healing process of bone fusion. We tried to investigate bone fusion rate in spine tumor surgery cases with perioperative radiation therapy (RT) and to analyze significant factors affecting successful bone fusion.

Methods : Study cohort was 33 patients who underwent spinal tumor resection and bone graft surgery combined with perioperative RT. Their medical records and radiological data were analyzed retrospectively. The analyzed factors were surgical approach, location of bone graft (anterior vs. posterior), kind of graft (autologous graft vs. allograft), timing of RT (preoperative vs. postoperative), interval of RT from operation in cases of postoperative RT (within 1 month vs. after 1 month) radiation dose (above 38 Gy vs. below 38 Gy) and type of radiation therapy (conventional RT vs. stereotactic radiosurgery). The bone fusion was determined on computed tomography images.

Result : Bone fusion was identified in 19 cases (57\%). The only significant factors to affect bony fusion was the kind of graft (75\% in autograft vs. 41 in allograft, $p=0.049$ ). Other factors proved to be insignificant relating to postoperative bone fusion. Regarding time interval of RT and operation in cases of postoperative RT, the time interval was not significant $(p=0.101)$.

Conclusion : Spinal fusion surgery which was combined with perioperative RT showed relatively low bone fusion rate (57\%). For successful bone fusion, the selection of bone graft was the most important.
\end{abstract}

Key Words : Spine tumor · Bone fusion · Bone graft · Radiation therapy.

\section{INTRODUCTION}

Metastatic tumors are the most common (97\%) tumors of the spine ${ }^{5}$. On the other hand, primary tumors of the spine are rare, their real incidence is unknown. Metastatic involvement of the vertebral column can occur in 50\% of patients diagnosed with cancer $^{11,26)}$ and can lead to unfavorable neurological sequelae in $5^{-14}$ of cancer patients ${ }^{12,16)}$. Spine tumor incidence is recently increasing owing to the increased life span and development of spinal tumor treatment ${ }^{27)}$. It is difficult to perform radical resection in the cases of vertebral body tumors with cord compres$\operatorname{sion}^{7)}$. Over the past few years, spinal tumor surgery was restricted to dorsal decompression of the spinal cord, and instrumentation options for stabilization were very limited ${ }^{4,8,22)}$. In recent years, surgical techniques for spinal tumors have been progressed. Nowadays, in addition to simple spinal decompression, complex surgical procedures such as vertebrectomy, circumferential fusion and multi-level fixation are also widely performed to in- crease the stability of vertebral column. For this reason, it is important to achieve successful bone fusion in spine tumor surgery $^{22)}$.

In the past years, conventional radiation therapy (RT) was the standard of care for patients with metastatic spine tumors ${ }^{4,10)}$. However as surgical techniques and instruments improve, surgical treatment followed by adjuvant RT is affording a longer survival period and better quality of life than RT alone ${ }^{10,13)}$. The benefit of perioperative RT has never been fully investigated, but it is assumed to be beneficial because in most cases spinal tumor resection does not achieve complete eradication of the microscopic tumor cells ${ }^{10}$. For this reason, tumor surgery is often accompanied by perioperative $\mathrm{RT}^{10)}$. Typically, in the patients who underwent interbody fusion perioperative irradiation is known to interfere with bone fusion and to make pseudoarthrosis causing a late fracture after surgery ${ }^{7,10)}$. The abnormalities observed in the irradiated tissue include the impairment of vascularization due to the high vulnerability of small vascular endo-

- Received : May 17, 2016 • Revised : August 4, 2016 •Accepted : August 31, 2016

- Address for reprints : Wonik Cho, M.D.

Department of Neurosurgery, Korea Cancer Center Hospital, Korea Institute of Radiological and Medical Science, 75 Nowon-ro, Nowon-gu, Seoul 01812, Korea

Tel : +82-2-970-1857, Fax : +82-2-970-1967, E-mail : 2631@kirams.re.kr

- This is an Open Access article distributed under the terms of the Creative Commons Attribution Non-Commercial License (http://creativecommons.org/licenses/by-nc/3.0) which permits unrestricted non-commercial use, distribution, and reproduction in any medium, provided the original work is properly cited. 
thelial cells, impairment of cell homeostasis with cellular apoptosis, and the accumulation of fibrosis ${ }^{18)}$. It is well known that high-dose irradiation delivers deleterious effects to bone tissue, including osteoradionecrosis, sclerosis, loss of bone mass, and bone fracture, in a dose- and time-dependent manner ${ }^{21}$. However, studies have been reported that low-dose irradiation promotes fracture healing through upregulation of vascular endothelial growth factor ${ }^{21,23)}$. Clinical studies on spinal fusion rate in perioperative radiation are insufficient ${ }^{7,10)}$.

In this retrospective study, we tried to investigate bone fusion rate in spine tumor surgery cases with perioperative RT and to analyze significant factors affecting successful bone fusion.

\section{MATERIALS AND METHODS}

The study was conducted on 33 patients who underwent a spinal tumor resection and bone graft reconstruction combined with perioperative RT from October 2004 to June 2015. Medical records and radiological data were retrospectively analyzed. Mean age was 51.2 years old (range, 18 to 73 years) and mean followup period was 30.4 months (range, 7 to 79 months). Patients consisted of 17 men and 16 women. Tumors were located as follows : nine tumors were located in the cervical region, 16 in thoracic, 6 in the lumbar and 2 in the sacral region. In this study, 23 patients had metastatic cancers and 10 patients primary spinal tumors. In surgical approach, anterior approach was performed in 16 cases and posterior approach in 17 cases. When the lesions were present only in the vertebral body, the anterior approach was employed. When the lesions were present in the pedicle and the posterior elements in addition to the vertebral body, the posterior approach was used. Interbody graft was used in 27 cases and posterior onlay graft in 6 cases. Two different types of materials such as autologous bone and allogeneic bone were used in Titanium Mesh Cage (TMC) for interbody fusion. As autologous bone graft, rib which was removed during surgery and the iliac cancellous bone were used. Each TMC was trimmed to match the sagittal alignment of the vertebral endplates.

With regard to the kind of RT, conventional RT was performed in 24 cases and stereotactic radiosurgery (SRS) in 9 cases. In terms of radiation timing, RT was given preoperatively in 12 cases and postoperatively in 21 cases, respectively. In the group undergoing the postoperative RT, the mean time interval between surgery and RT was 4 weeks (range, 2 to 15 weeks). In this group, 11 patients received the RT within one month and 10 patients received the RT after one month. Seventeen patients received a radiation dose lower than 38 gray and 16 patients received a radiation dose higher than 38 gray.

The success of the bone fusion was determined by a computed tomography (CT) scan images. The bone fusion was assessed on the basis of the Bridwell grading system ${ }^{8)}$. Fig. 1 shows the Bridwell grading system. Grade I implies complete fusion (completely remodeled with trabeculae across disc space). Grade II implies partial fusion (graft intact but not completely remodeled). Grade III implies unipolar pseudarthrosis (graft intact but not fused). Grade IV implies bipolar pseudarthrosis (lucency along an entire border of the graft).

The factors affecting the bone fusion rate were surgical approaches, locations of bone graft (anterior or posterior), kinds of bone graft (autologous bone or allogeneic bone), radiation timing (before or after surgery), methods of radiation therapy (conventional RT or SRS), time interval between surgery and radiation therapy (within 1 month or after 1 month), and dose of irradiation (above 38 Gy or below $38 \mathrm{~Gy}$ ).

Statistical Package for the Social Sciences (SPSS) version 18.0 (SPSS Inc., Chicago, IL, USA) was used for statistical analysis. The chi-square and Fisher's exact tests were used to compare means. Two-by-two crosstabs was adopted for categorical data analysis. $p$-values of 0.05 (2-tailed) were considered significant.

\section{RESULTS}

Total 33 patients underwent the spinal tumor surgery combined with perioperative RT. Data from the study population are summarized in Table 1. According to the follow-up study, 19 patients showed successful bone fusion and 14 patients showed fusion failure. The overall fusion rate was $57 \%$. Among 14 patients who failed in the bone fusion, 2 patients had symptoms associated with bone fusion failure. In 3 patients, the bone
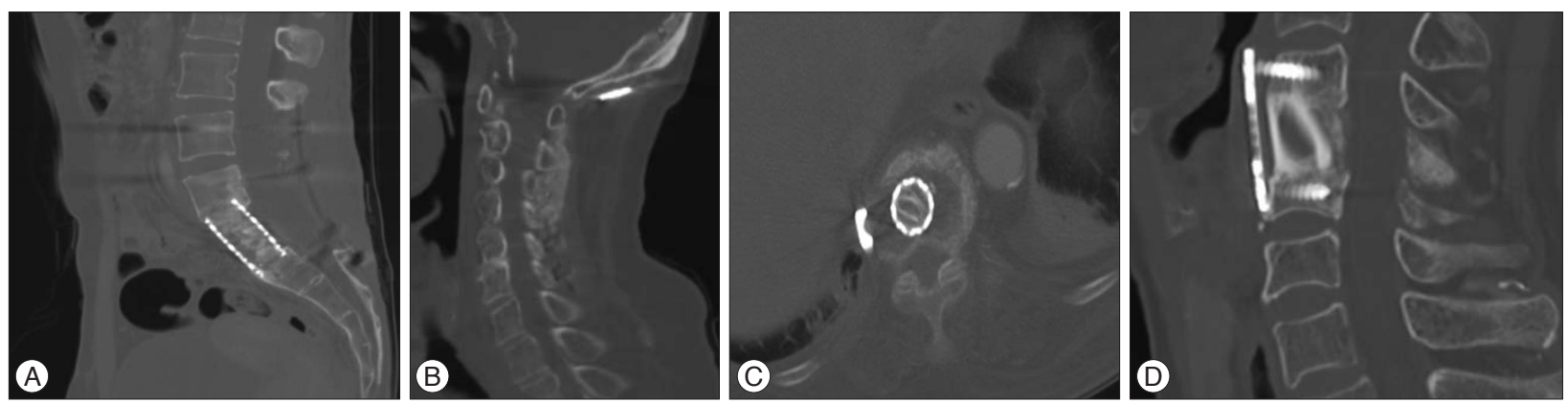

Fig. 1. A : Fusion state, grade 1 by Bridwell grading system. Bone remodeling and trabeculae are seen between cage and adjacent vertebral bodies. B : Fusion state, Post instrumentation and on lay graft with allobone; grade 2 indicates probable fusion (graft intact, not fully remodeled). $\mathrm{C}:$ Non-fusion state; grade 3 by Bridwell grading system (graft intact but lucency where it contacted the host bone surface). D : Non-fusion state; grade 4 by Bridwell grading system (graft resorbed). 
Table 1. Summary of 33 spine tumor patients who underwent fusion surgery

\begin{tabular}{|c|c|c|c|c|c|c|c|c|c|c|c|}
\hline $\begin{array}{l}\text { Case } \\
\text { no. }\end{array}$ & $\begin{array}{l}\text { Age/ } \\
\text { Sex }\end{array}$ & Primary tumor & $\begin{array}{l}\text { Involve } \\
\text { level }\end{array}$ & $\begin{array}{c}\text { Op. } \\
\text { position }\end{array}$ & $\begin{array}{l}\text { RT } \\
\text { timing }\end{array}$ & $\begin{array}{c}\text { Time to } \\
\text { RT }\end{array}$ & $\begin{array}{l}\text { Graft } \\
\text { type }\end{array}$ & $\begin{array}{l}\text { Location } \\
\text { of bone graft }\end{array}$ & $\begin{array}{c}\text { F/u period } \\
\text { (months) }\end{array}$ & $\begin{array}{l}\text { Radiation } \\
\text { dose (Gy) }\end{array}$ & $\begin{array}{l}\text { Fusion } \\
\text { success }\end{array}$ \\
\hline 1 & $50 / \mathrm{M}$ & $\mathrm{HCC}$ & $\mathrm{C} 4$ & Sup & Post & 3 & Auto & A & 25 & 30 & Yes \\
\hline 2 & $70 / \mathrm{M}$ & Breast ca & $\mathrm{T} 11,12$ & Lat & Pre & 28 & Auto & A & 78 & 36 & Yes \\
\hline 3 & $59 / \mathrm{M}$ & MFH & $\mathrm{T} 8$ & Lat & Post & 50 & Auto & A & 9 & 50 & Yes \\
\hline 4 & $67 / \mathrm{M}$ & Thyroid ca & $\mathrm{C} 4$ & Pro & Post & 1 & Auto & A & 72 & 30 & Yes \\
\hline 5 & $23 / \mathrm{F}$ & GCT & $\mathrm{C} 3$ & Com & Post & 2 & Auto & A & 58 & 45 & Yes \\
\hline 6 & $61 / \mathrm{M}$ & Colon ca & $\mathrm{T} 2$ & Pro & Post & 2 & Auto & A & 14 & 30 & Yes \\
\hline 7 & $68 / \mathrm{M}$ & MM & C6 & Pro & Post & 3 & Auto & A & 52 & 30 & Yes \\
\hline 8 & $70 / \mathrm{F}$ & Colon ca & $\mathrm{C} 4$ & Sup & Post & 45 & Allo & A & 30 & 30 & No \\
\hline 9 & $66 / \mathrm{M}$ & Chordoma & C6 & Sup & Post & 1 & Allo & A & 40 & 50 & Yes \\
\hline 10 & $58 / \mathrm{F}$ & Thyroid ca & $\mathrm{C} 6,7$ & Sup & Pre & 26 & Allo & A & 18 & 39 & No \\
\hline 11 & $58 / \mathrm{M}$ & Colon ca & $\mathrm{T} 2$ & Pro & Pre & 4 & Allo & A & 30 & 30 & No \\
\hline 12 & $62 / \mathrm{M}$ & Lung ca & T11 & Pro & Pre & 7 & Allo & A & 7 & 37.5 & No \\
\hline 13 & $35 / \mathrm{F}$ & Lung ca & T7 & Lat & Post & 2 & Auto & A & 10 & 30 & No \\
\hline 14 & $54 / \mathrm{F}$ & Chordoma & C5 & Sup & Post & 4 & Auto & A & 74 & 50 & Yes \\
\hline 15 & $66 / F$ & Chordoma & S2-5 & Pro & Post & 15 & Allo & $\mathrm{P}$ & 79 & 60 & No \\
\hline 16 & $59 / \mathrm{F}$ & Breast & $\mathrm{L} 2-5$ & Pro & Post & 9 & Allo & $\mathrm{P}$ & 19 & 37.5 & Yes \\
\hline 17 & $21 / \mathrm{M}$ & Ewing's sarcoma & T5, 6 & Pro & Post & 1 & Allo & A & 28 & 37.5 & No \\
\hline 18 & $72 / \mathrm{F}$ & Colon ca & $\mathrm{T} 10$ & Lat & Post & 1 & Auto & A & 8 & 34 & No \\
\hline 19 & $18 / \mathrm{M}$ & Osteosarcoma & $\mathrm{L} 2$ & Lat & Pre & 28 & Auto & A & 58 & 90 & Yes \\
\hline 20 & $56 / \mathrm{F}$ & Thyroid ca & $\mathrm{L} 2,3$ & Pro & Pre & 50 & Allo & A & 46 & 40 & Yes \\
\hline 21 & $50 / \mathrm{M}$ & $\mathrm{HCC}$ & L5 & Pro & Post & 1 & Auto & $\mathrm{P}$ & 7 & 30 & No \\
\hline 22 & $18 / \mathrm{M}$ & MUO & $\mathrm{T} 8$ & Pro & Post & 2 & Allo & A & 48 & 37.5 & Yes \\
\hline 23 & $39 / \mathrm{F}$ & Breast ca & $\mathrm{L} 2$ & Lat & Pre & 2 & Allo & A & 34 & 30 & No \\
\hline 24 & $45 / \mathrm{F}$ & Breast ca & T10 & Lat & Pre & 3 & Auto & A & 25 & 30 & No \\
\hline 25 & $49 / \mathrm{F}$ & MPNST & $\mathrm{C} 2,3$ & Pro & Pre & 45 & Auto & $\mathrm{P}$ & 26 & 60 & Yes \\
\hline 26 & $73 / \mathrm{M}$ & MM & $\mathrm{C} 2,3$ & Pro & Post & 1 & Allo & $\mathrm{P}$ & 11 & 30 & Yes \\
\hline 27 & $65 / \mathrm{M}$ & Sigmoid ca & $\mathrm{L} 2$ & Com & Pre & 26 & Allo & A & 8 & 75 & No \\
\hline 28 & $60 / \mathrm{M}$ & Ureter ca & T12 & Pro & Pre & 4 & Allo & A & 10 & 58 & Yes \\
\hline 29 & $57 / \mathrm{F}$ & Thyroid ca & T8, 9 & Pro & Pre & 7 & Allo & A & 9 & 50 & No \\
\hline 30 & $40 / \mathrm{F}$ & Leiomyosarcoma & L2 & Lat & Post & 2 & Auto & A & 7 & 58 & Yes \\
\hline 31 & $49 / \mathrm{M}$ & Chondrosarcoma & T3 & Pro & Post & 4 & Allo & A & 21 & 54 & No \\
\hline 32 & $24 / \mathrm{M}$ & Osteosarcoma & $\mathrm{T} 8$ & Pro & Post & 15 & Auto & $\mathrm{P}$ & 26 & 60 & Yes \\
\hline 33 & $26 / \mathrm{F}$ & Osteosarcoma & S1 & Sup & Post & 9 & Allo & $\mathrm{P}$ & 19 & 60 & Yes \\
\hline
\end{tabular}

No : number, M : male, F : female, HCC : hepatocelllar carcinoma, MFH : malignant fibrous histocytosis, MM : multiple myeloma, ca : cancer, MPNST : malignant peripheral nerve sheath tumor, MUO : mass of unknown origin, Sup : supine, Pro : prone, Com : combine (prone+lateral), Lat : Lateral, Post : postoperative, Pre : preoperative, Allo : allogenic bone, Auto : autologous bone, A : anterior, P : posterior, F/U : follow up, Gy : gray

fusion failure worsened their pain. There was no patient who had neurological symptoms due to the bone fusion failure. There was no patient who showed instrumentation failure. Among 14 patients who failed in the bone fusion, there was no patient who had severe instability. One patient required reoperation, but did not undergo the surgery due to poor systemic condition by tumor progression.

Regarding surgical approach, 9 patients out of 16 showed successful bone fusion in anterior approach and 11 patients out of 17 showed successful bone fusion in posterior approach. This difference does not reach statistical significance $(p=0.971)$. The success bone fusion rates of anterior and posterior approaches were 56 and 64, respectively. There was no statistically signifi- cant difference. In position of bone graft, the patients with posterior position showed relatively slightly higher success rate than the patients with anterior position (posterior position : $59 \%$ versus anterior position : $50 \%$ ), but this difference does not reach statistical significance $(p=0.678)$. With regard to kinds of bone graft, among 17 patients using allogeneic bone, 7 patients had success in bone fusion. Among 16 patients using autogenous bone, 12 patients had success in bone fusion. The successful bone fusion rates of the autogenous bone and allogeneic bone were $75 \%$ and $41 \%$, respectively. There was statistically significant difference $(p=0.049)$. Bone fusion rates were compared in terms of factors relating to surgical procedure in Fig. 2.

In Fig. 3, bone fusion rates were compared in terms of factors 
associated with irradiation. Although higher fusion rate is seen in cases of postoperative RT than in cases of preoperative RT (post-operative : $61 \%$ vs. pre-operative : $50 \%$ ), but there was no statistical significance $(p=0.716)$. Among 11 patients who underwent RT within 1 month after surgery, 5 patients had successful fusion (45\%). Ten patients underwent RT after 1 month after

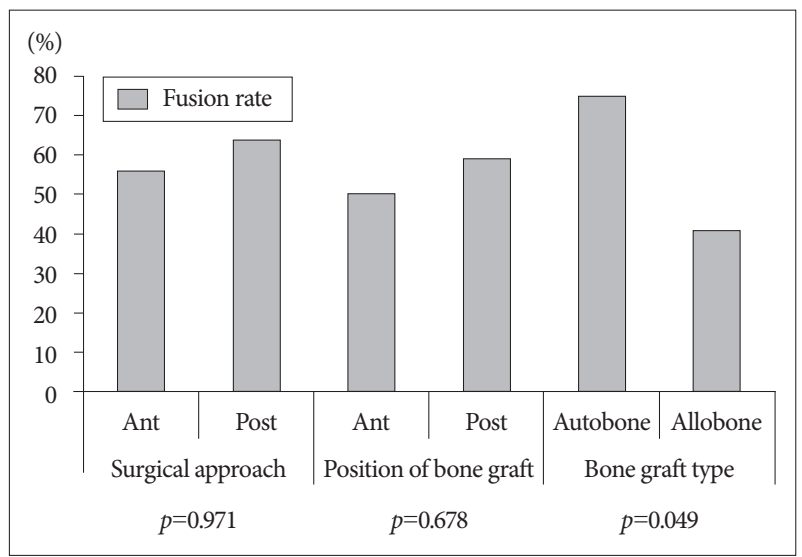

Fig. 2. Fusion success rate according to each of the prognostic factors on surgical aspect. The kind of bone graft was only significant factor related successful bony fusion $(p=0.049)$. surgery, and 8 patients had successful fusion (80\%). But this difference does not reach statistical significance $(p=0.104)$. In terms of RT types, 9 patients out of 11 patients with SRS had successful fusion (81\%), but 10 patients out of 22 patients with conventional RT had successful fusion (45\%). The patients with SRS showed relatively higher bone fusion rate than the patients with conventional RT, but this difference does not reach statistical significance $(p=0.101)$. In patients who received a dose of RT below $38 \mathrm{~Gy}$, the bone fusion rate was 68 . In patients who had a dose of RT above $38 \mathrm{~Gy}$, the bone fusion rate was $47 \%$. However, there was no statistical significance $(p=0.208)$.

In summary, the bone fusion was not affected by factors such as locations of bone graft, surgical approaches, doses of RT, kinds of RT and time interval between surgery and RT. The most important factor affecting the spine fusion in patients who undergo the spinal tumor surgery combined with the perioperative RT was the kind of bone graft to be used (Table 2).

\section{DISCUSSION}

Treatment of neoplastic spinal lesions continues to present a major challenge ${ }^{14)}$.

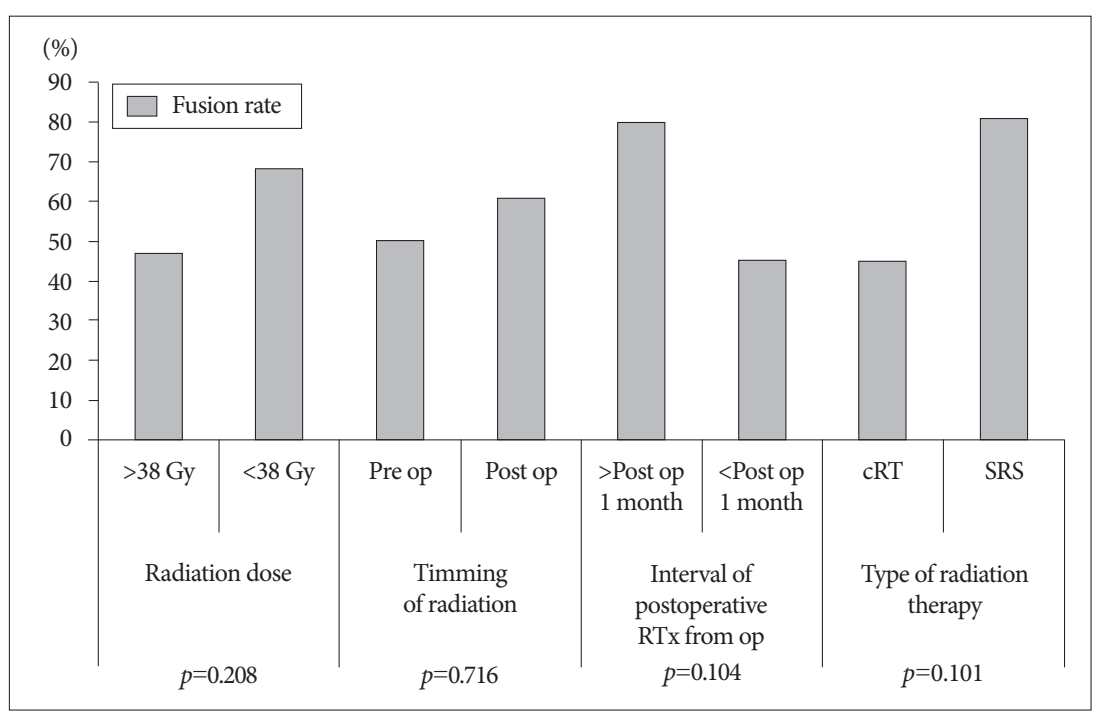

Fig. 3. Fusion success rate according to each of the prognostic factors on irradiation aspect. There was no significant factors relating to successful bony fusion on irradiation aspect.

Table 2. Prognostic factor relating to bone fusion

\begin{tabular}{llll}
\hline \multicolumn{1}{c}{ Prognostic factors } & \multicolumn{1}{c}{ Variables } & Fusion rate & $p$ value \\
\hline Surgical aspect & & & \\
$\quad$ Surgical approach & Ant. approach vs. Post. approach & $56 \%$ vs. $64 \%$ & 0.971 \\
$\quad$ Position of bone graft & Ant. position vs. Post. position & $50 \%$ vs. $59 \%$ & 0.678 \\
$\quad$ Bone graft type & Autologous bone vs. Allogenic bone & $75 \%$ vs. $41 \%$ & $0.049^{*}$ \\
Irradiation aspect & & & 0.208 \\
$\quad$ Radiation dose & Over 38 Gy vs. Below 38 Gy & $47 \%$ vs. $68 \%$ & 0.716 \\
$\quad$ Timing of radiation & Pre-operative vs. Post-operative & $50 \%$ vs. $61 \%$ & $0.104^{\dagger}$ \\
$\quad$ Interval of postoperative RT from op & Within 1 month vs. After 1 month & $45 \%$ vs. $80 \%$ & $45 \%$ vs. $81 \%$ \\
$\quad$ Type of radiation therapy & Conventional RT vs. SRS & $0.101^{\dagger}$ \\
\hline
\end{tabular}

${ }^{*}$ Significant at $p<0.05,{ }^{\prime}$ It was not statistically difference but showed high tendency. vs. : versus, Ant : anterior, Post : posterior, RT : radiation therapy, SRS : stereotatic radiosurgery, Gy : gray 
In recent years, advance of technology and surgical methods resulted in better surgical results for patients who underwent spinal tumor surgery ${ }^{1,10}$, and studies showed that combined treatment of surgery and RT would provide better outcome compared with radiation alone ${ }^{10)}$. Adjuvant irradiation to the spine is now common practice for malignant spinal neoplasm, although irradiation and surgery have never been compared with surgery alone in a large-scale trial. The rationale for RT is to achieve local control of the residual mass in the resection site, which is a common practice in other oncologic fields ${ }^{15)}$. In patients with metastatic tumor, Townsend et al. ${ }^{25)}$ reported that the group received metastatic tumor surgery plus postoperative RT had a striking survival advantage over the surgery-only group, with actuarial median survival duration of 12.4 months versus 3.3 months. For this reason, perioperative RT has been used as a treatment for spine tumors.

In general, irradiation causes changes in normal tissue surrounding the tumor, weakening the bones and interfering with tissue healing and fusion process ${ }^{2,3}$. This delay in union may be caused by the direct cytotoxic effects of radiation on proliferating cells or the intense vasculitis induced by irradiation injury or it may be related to the alteration in vascularity from both the vasculitis induced by the irradiation injury and suppression of angiogenesis ${ }^{20)}$. Long after acute phase, radiation-induced osteonecrosis and the dense hypovascular scar left in the radiation bed may leave a poor biologic environment for fusion ${ }^{20)}$. It is well known that high-dose irradiation delivers deleterious effects to bone tissue, including osteoradionecrosis, sclerosis, loss of bone, and bone fracture, in a dose- and time-dependent manner ${ }^{17,18,24)}$. Emery et al. ${ }^{6}$ reported that long bone fractures after irradiation in laboratory animals are associated with a high pseudarthrosis rate, delayed union, decreased strength and decreased periosteal osteoblastic proliferation, decreased formation of cartilage and osteoid, and decreased vascularity after irradiation. Another study showed that the frequency of delayed unions for extracorporeally irradiated autografts in rats has been related to the irradiation dose $\mathrm{e}^{19)} ; 16 \%$ at $1 \mathrm{kGy}, 24 \%$ at $5 \mathrm{kGy}$, and $100 \%$ at 25 $\mathrm{kGy}$. Emery et al. ${ }^{7)}$ reported that patients who had anterior vertebrectomy and bone strut grafts fusion for spinal neoplasm with irradiation doses greater than $4000 \mathrm{cGy}$ showed increased pseudarthrosis $(p<0.003)$.

Several articles reporting clinical data on spine fusion surgery combined with RT were found. Lewandrowski et al. ${ }^{14)}$ reported that 28 cases out of the 30 patients with structural allografts (93\%) showed radiographic evidence of incorporation (fusion Grades I or II) at follow-up examinations in spite of adjuvant chemotherapy and RT. Emery et al. ${ }^{7)}$ revieiwed 25 patients who underwent anterior vertebrectomy, autologous bone strut insertion, and perioperative RT. They found that 21 patients were judged to have a solid arthrodesis and four patients had pseudarthrosis. Their data showed high bone fusion rate (84\%). But in our data, bone fusion was identified in 19 cases (overall fusion rate $57 \%$ ), which is relatively low bone fusion rate. The reason is thought to be the character of bone graft we used. The allograft was used in 50 of the patients and all the allografts were cancellous bone chip, not structural allograft. Structural graft is composed of cortical and cancellous bone. Cancellous graft is completely replaced in time by creeping substitution, while cortical grafts remain an admixture of necrotic and viable bone for a prolonged period of time ${ }^{9)}$. Therefore structural allograft has higher bone fusion than allograft bone chip. Goldberg et al. ${ }^{9)}$ reported autogenous tricortical iliac crest is used in the majority of case, as it is believed to have a better healing potential than allograft. Autografts are usually implanted fresh and often osteogenic. However, allografts are more slowly and less completely replaced by host bones because they invoke both local and systemic immune responses that destroy the osteoinductive and conductive processes.

With respect to timing of perioperative irradiation, Emery et al. ${ }^{6}$ using a canine model of vertebrectomy and strut grafting, found that immediate postoperative irradiation was detrimental to graft healing but preoperative irradiation had no adverse effect. Bouchard et al. ${ }^{3)}$ showed that immediate postoperative radiation interfered with the healing of posterior fusions in a rabbit model, although the adverse effect was less if RT was given 3 weeks or more after the fusion and grafting procedure $(p<0.05)$. In rabbit model, control group and the delayed irradiation group ( 3 weeks or more after the fusion) had the highest histologic scores and more mature fusion mass. The immediate postoperative irradiation group had the worst results, with consistent fibrous union of the graft. Boden et al. ${ }^{2)}$ also suggested that a delay in postoperative radiation for 3 to 6 weeks would be beneficial to the healing process. According to our data, bone fusion was not influenced by timing of RT ( $p=0.716)$. However in patients underwent RT after 1 month after surgery showed higher bone fusion rate $(80 \%)$.

Harel et al. ${ }^{10)}$ reported that the fusion rates of patients who underwent spinal tumor resection and bone graft surgery com-

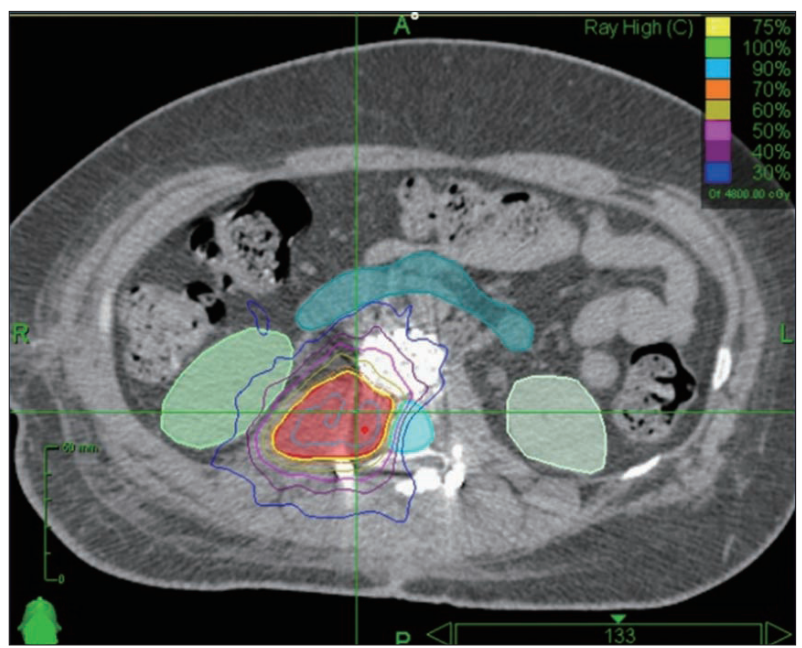

Fig. 4. A case of perioperative stereotactic radiosurgery planning. There was relative sparing of the ventral and dorsal fusion surface. 
bined with perioperative RT (8 cases of SRS and 7 cases of conventional RT) were $50 \%$ in the SRS group versus $17 \%$ in the conventional RT group. According to our data, SRS is relatively higher fusion rate than conventional RT ( $81 \%$ in SRS vs. $45 \%$ in conventional RT). But this was not statistically significant $(p=0.101)$. The reason patients who received the SRS treatment showed a relatively high fusion rate is that fusion bed can be out of radiation field (Fig. 4).

Although we found some informative data on spinal bone fusion associated with perioperative RT, our study has some limitations. Collected data are so heterogenous; the patients with different surgical technique (interbody fusion or posterior fusion), different RT timing (preoperative or postoperative) and different kinds of bone graft are mixed. Fusion rate varies because biomechanics and epidermiology of tumors are different depending on tumor location. But we can't classify the cases according to tumor location due to the number of study population was small.

\section{CONCLUSION}

It is important to achieve successful bone fusion in spine tumor surgery. When spinal fusion surgery was combined with the perioperative RT, the bone fusion rate showed a relatively low rate (57\%). Statistically the only factor affecting the spinal fusion was to use autologus bone graft. Type of radiation (SRS), time interval between RT after surgery ( $>1$ month) were not statistically difference but showed high fusion rate compared to the other groups. Although it has statistically limitation, there have considerable factors for successful spinal fusion. For the successful bone fusion, some technical strategies are considered. First, the use of autologus bone graft is recommended rather than allogenic bone graft. Second, the adoption of SRS protects bone fusion bed more efficiently than convention RT. Third, when the postoperative RT is considered, it is best to delay RT from the operation time for as long as possible.

\section{References}

1. Bartels RH, Feuth T, van der Maazen R, Verbeek AL, Kappelle AC, André Grotenhuis J, et al. : Development of a model with which to predict the life expectancy of patients with spinal epidural metastasis. Cancer $110: 2042-2049,2007$

2. Boden $\mathrm{SD}$ : The biology of posterolateral lumbar spinal fusion. Orthop Clin North Am 29 : 603-619, 1998

3. Bouchard JA, Koka A, Bensusan JS, Stevenson S, Emery SE : Effects of irradiation on posterior spinal fusions. A rabbit model. Spine (Phila Pa 1976) 19 : 1836-1841, 1994

4. Chang EL, Shiu AS, Mendel E, Mathews LA, Mahajan A, Allen PK, et al. : Phase I/II study of stereotactic body radiotherapy for spinal metastasis and its pattern of failure. J Neurosurg Spine 7 : 151-160, 2007

5. Ciftdemir M, Kaya M, Selcuk E, Yalniz E : Tumors of the spine. World J Orthop $7:$ 109-116, 2016

6. Emery SE, Brazinski MS, Koka A, Bensusan JS, Stevenson S : The biological and biomechanical effects of irradiation on anterior spinal bone grafts in a canine model. J Bone Joint Surg Am 76 : 540-548, 1994

7. Emery SE, Hughes SS, Junglas WA, Herrington SJ, Pathria MN : The fate of anterior vertebral bone grafts in patients irradiated for neoplasm. Clin Orthop Relat Res (300) : 207-212, 1994

8. George R, Jeba J, Ramkumar G, Chacko AG, Tharyan P : Interventions for the treatment of metastatic extradural spinal cord compression in adults. Cochrane Database Syst Rev 4 : CD006716, 2015

9. Goldberg VM, Stevenson S : Natural history of autografts and allografts. Clin Orthop Relat Res (225) : 7-16, 1987

10. Harel R, Chao S, Krishnaney A, Emch T, Benzel EC, Angelov L : Spine instrumentation failure after spine tumor resection and radiation : comparing conventional radiotherapy with stereotactic radiosurgery outcomes. World Neurosurg 74:517-522, 2010

11. Heidecke V, Rainov NG, Burkert W : Results and outcome of neurosurgical treatment for extradural metastases in the cervical spine. Acta Neurochir (Wien) $145: 873-880$; discussion 880-881, 2003

12. Ibrahim A, Crockard A, Antonietti P, Boriani S, Bünger C, Gasbarrini A, et al. : Does spinal surgery improve the quality of life for those with extradural (spinal) osseous metastases? An international multicenter prospective observational study of 223 patients. Invited submission from the Joint Section Meeting on Disorders of the Spine and Peripheral Nerves, March 2007. J Neurosurg Spine 8 : 271-278, 2008

13. Lee MH, Lee SH, Kim ES, Eoh W, Chung SS, Lee CS : Survival-related factors of spinal metastasis with hepatocellular carcinoma in current surgical treatment modalities : a single institute experience. J Korean Neurosurg Soc 58 : 448-453, 2015

14. Lewandrowski KU, Hecht AC, DeLaney TF, Chapman PA, Hornicek FJ, Pedlow FX : Anterior spinal arthrodesis with structural cortical allografts and instrumentation for spine tumor surgery. Spine (Phila Pa 1976) 29 : 1150-1158; discussion 1159, 2004

15. Mantravadi RV, Skolnik EM, Applebaum EL : Complications of postoperative and preoperative radiation therapy in head and neck cancers. A comparative study. Arch Otolaryngol 107 : 690-693, 1981

16. Patchell RA, Tibbs PA, Regine WF, Payne R, Saris S, Kryscio RJ, et al. : Direct decompressive surgical resection in the treatment of spinal cord compression caused by metastatic cancer : a randomised trial. Lancet 366 : 643-648, 2005

17. Peyre HM, Coffigny H, Reillaudou M, Beaumatin J, Morin M, Luccioni C : Transformation by radiation of rat foetal glial cells. Int J Radiat Biol $76: 87-94,2000$

18. Phulpin B, Dolivet G, Marie PY, Poussier S, Gallet P, Leroux A, et al. : Re-assessment of chronic radio-induced tissue damage in a rat hindlimb model. Exp Ther Med $1: 553-560,2010$

19. Poffyn B, Sys G, Mulliez A, Van Maele G, Van Hoorebeke L, Forsyth R, et al. : Extracorporeally irradiated autografts for the treatment of bone tumours : tips and tricks. Int Orthop 35 : 889-895, 2011

20. Sanpakit S, Mansfield TL, Liebsch J : Role of onlay grafting with minimal internal fixation for occipitocervical fusion in oncologic patients. J Spinal Disord 13 : 382-390, 2000

21. She C, Shi GL, Xu W, Zhou XZ, Li J, Tian Y, et al. : Effect of low-dose Xray irradiation and Ti particles on the osseointegration of prosthetic. J Orthop Res 2016 Jan 30 [Epub]. http : //dx.doi.org/10.1002/jor.23179.

22. Sherman RM, Waddell JP : Laminectomy for metastatic epidural spinal cord tumors. Posterior stabilization, radiotherapy, and preoperative assessment. Clin Orthop Relat Res (207) : 55-63, 1986

23. Song XS, Zhou XZ, Zhang G, Dong QR, Qin L : Low-dose X-ray irradiation promotes fracture healing through up-regulation of vascular endothelial growth factor. Med Hypotheses 75 : 522-524, 2010

24. Takahashi S, Sugimoto M, Kotoura Y, Sasai K, Oka M, Yamamuro T : Long-term changes in the haversian systems following high-dose irradiation. An ultrastructural and quantitative histomorphological study. J Bone Joint Surg Am 76 : 722-738, 1994

25. Townsend PW, Rosenthal HG, Smalley SR, Cozad SC, Hassanein RE : Impact of postoperative radiation therapy and other perioperative factors 
on outcome after orthopedic stabilization of impending or pathologic fractures due to metastatic disease. J Clin Oncol 12 : 2345-2350, 1994

26. Wong DA, Fornasier VL, MacNab I : Spinal metastases : the obvious, the occult, and the impostors. Spine (Phila Pa 1976) 15 : 1-4, 1990
27. Yu JI, Park HC, Ahn YC, Chung Y, Koom WS, Song SY : Variation in practice patterns of korean radiation oncologists for spine metastasis between 2009 and 2014. Cancer Res Treat 48 : 1102-1109, 2016 